\title{
Suppression of LASP-1 attenuates the carcinogenesis of prostatic cancer cell lines: Key role of the NF-кB pathway
}

\author{
WENDONG SUN ${ }^{1}$, LIQIANG GUO ${ }^{1}$, GUANGFENG SHAO ${ }^{1}$, XIANGGUO LIU ${ }^{2}$, \\ YONG GUAN $^{1}$, LING SU ${ }^{2}$ and SHENGTIAN ZHAO ${ }^{1,3}$ \\ ${ }^{1}$ Department of Urology, The Second Hospital of Shandong University, Jinan, Shandong 250033; \\ ${ }^{2}$ Shandong University School of Life Sciences, Jinan, Shandong 250100; ${ }^{3}$ Affiliated Hospital of \\ Shandong University of Traditional Chinese Medicine, Jinan, Shandong 250011, P.R. China
}

Received May 17, 2016; Accepted June 11, 2016

DOI: $10.3892 /$ or.2016.5223

\begin{abstract}
Prostate cancer (PCa) is one of the most frequently diagnosed cancers among males worldwide and causes a considerable number of deaths each year. One of the newly explored targets for the development of therapies against $\mathrm{PCa}$ is LIM and SH3 protein 1 (LASP-1). In the present study, the function of LASP-1 in the oncogenesis and metastasis of PCa was investigated using a series of in vitro experiments. Moreover, the mechanism through which LASP-1 exerted its effect on the carcinogenesis of PCa was also explored. The expression levels of LASP-1 in clinical PCa specimens were determined both at the mRNA and protein levels. Afterwards, the activity of LASP-1 in human PCa cell lines PC3 and DU145 was inhibited using a short hairpin RNA (shRNA) interfering method. The effects of LASP-1 knockdown on the cell growth, apoptosis, cell cycle distribution, migration and invasion were assessed. It was demonstrated that the expression of LASP-1 was significantly higher in the clinical PCa tissues than the level in the corresponding para-carcinoma tissues. Following the knockdown of the LASP-1 gene in human PCa cell lines, the viability, migration and invasion of the cancer cells were decreased. It was also demonstrated that the change in the cell viability and motile ability were associated with an induction of cell apoptosis and G1 phase cell cycle arrest. Based on the results of the detection of the expression of NF- $\kappa \mathrm{B}$ related factors, it was indicated that LASP-1 may affect the carcinogenesis of $\mathrm{PCa}$ through a NF- $\mathrm{B}$ inhibition-dependent manner. Although the detailed explanation of the mechanism of LASP-1 in the carcinogenesis of PCa requires further elucidation, the present study highlights the potential of LASP-1 as a promising therapeutic target to ameliorate the oncogenesis and metastasis of PCa.
\end{abstract}

Correspondence to: Dr Shengtian Zhao, Department of Urology, The Second Hospital of Shandong University, 247 Beiyuan Street, Jinan, Shandong 250033, P.R. China

E-mail: zhaoshengtian@sdu.edu.cn

Key words: prostate cancer, LASP-1, NF-кB p65, IкB $\alpha$

\section{Introduction}

Prostate cancer (PCa) continues to be the most frequently diagnosed cancer among males and is the cause of severe health issues in males worldwide (1). According to 2015 statistics (2), $\mathrm{PCa}$ ranks second as a leading cause of cancer-related deaths in men in the USA. Although most cases of PCa are curable, there is still $10-20 \%$ of PCa patients with poor prognosis who develop castration-resistant prostate cancer (3). Generally, the risk factors for PCa may be divided into an exogenous category, including aging, oxidative stress and family, and an endogenous category, including a rich fat diet and environmental agents $(4,5)$. In addition to the multiple risk factors, the prognosis following traditional treatment modalities also varies greatly. The overall survival time of patients may range from 15 years to 2 years without a clear explanation $(6,7)$. Thus, it is difficult to provide accurate clinical recommendations for $\mathrm{PCa}$.

In recent years, studies regarding the dysregulation of microRNAs in PCa have been extensively performed. Molecular alterations associated with the miR regulation derived from these investigations have provided various potential targets involved in the oncogenesis and development of $\mathrm{PCa}$ (8-11). One of these newly explored targets is the LIM and SH3 protein 1 (LASP-1), which encodes a membrane-bound protein of 261 amino acids containing an N-terminal LIM domain $(12,13)$. Although the exact biological function of LASP-1 has yet to be revealed, its association with multiple malignancies, including breast, colorectal, hepatocellular and bladder cancer, is well established (14-18). However, even with extensive interest in the function of LASP-1 in carcinogenesis, little effort has been made to elucidate the role of LASP-1 in $\mathrm{PCa}$, not to mention assessment of its potential as an anti-PCa therapy.

A well establishment pathway involved in the growth of multiple types of tumor cells is nuclear transcription factor $\mathrm{NF}-\kappa \mathrm{B}(19,20)$. This factor regulates the expression of immediate-early and stress response genes which are mainly implicated in acute inflammatory responses in various diseases. In addition, regulation of the level of NF- $\kappa \mathrm{B}$ has achieved considerable outcome in the treatment of various cancer types $(21,22)$. Regarding PCa, the critical role of $\mathrm{NF}-\kappa \mathrm{B}$ in the proliferation of PCa cells was also verified $(23,24)$, but 
to the best of our knowledge, no studies have given attention to the association between LASP-1 and NF- $\kappa \mathrm{B}$ in PCa. Thus, a comprehensive study attempting to reveal the interaction between the two indicators may promote the development of anti-PCa therapies and the understanding of the mechanism of the carcinogenesis of PCa.

In the present study, for the first time, the expression level of LASP-1 in human PCa clinical samples was investigated. Then, the expression of LASP-1 in human PCa cell lines PC3 and DU145 was regulated by transfection of specific short hairpin RNA (shRNA) and the influence of LASP-1 knockdown on cell growth, cell cycle distribution, apoptosis, migration and invasion was detected. To preliminarily reveal the mechanism through which LASP-1 exerts its function in PCa cells, the expression levels of NF- $\kappa \mathrm{B}$-related molecules were quantified by RT-qPCR and western blot assay. It was expected that the function of LASP-1 in PCa and the pathway through which LASP-1 contributes to the formation and progression of PCa could be partially elucidated by the findings in the present study.

\section{Materials and methods}

Chemicals and cell cultures. Antibodies against LASP-1, NF- $\kappa$ B subunit p65 (P65), I $\kappa$ B $\alpha$ and GAPDH were purchased from Promega (Madison, WI, USA). Human PCa cell lines DU145 and PC3 were obtained from the American Type Culture Collection (ATCC; Manassas, VA, USA). DU145 cells were cultured in Eagle's minimum essential medium (EMEM) supplemented with $1.8 \mathrm{mM} \mathrm{CaCl}_{2}$ and $\mathrm{PC} 3$ cells were cultured in F-12 medium. Both media were supplemented with $10 \%$ fetal bovine serum (FBS) and $1 \%$ penicillin/streptomycin. For experimental use, cells from three to six passages were employed.

Patients and PCa specimen collection. For detection of LASP-1 expression in clinical samples, 15 pairs of $\mathrm{PCa}$ and para-carcinoma tissues were collected from patients at The Second Hospital of Shandong University. All the samples met the following criteria: i) carcinoma tissues collected from nephrectomy were defined as primary prostatic adenocarcinoma while para-carcinoma samples were collected from kidney tissues of benign prostatic hyperplasia via renipuncture; ii) detailed information was available concerning the clinicopathological and prognostic characteristics of all the patients enrolled in the present study (Table I). Patients who had undergone any therapy for PCa before the surgical procedure were excluded. The present study was approved by the Ethics Committee of the Second Hospital of Shandong University. The Ethics Committee approved the related screening, inspection, and data collection of the patients, and all subjects signed a written informed consent form. All studies were undertaken following the provisions of the Declaration of Helsinki.

Knockdown of the LASP-1 gene in PCa cells by shRNA. The target sequence for LASP-1-specific shRNA (5'-GAAUC AAGAAGACCCAGGATT-3') and the negative control (NC) shRNA (5'-UUCUCCGAACGUGUCACGUTT-3') were obtained from GeneChem Biotech (Shanghai, China). Two PCa lines were grouped into two treatment groups, respec- tively: cells treated with NC-shRNA and cells treated with LASP-1-shRNA. Transfections were conducted using transfection agents obtained from Applygen Technologies Inc. (Beijing, China) (no. c1507) according to the manufacturer's instructions. Stable transfected cells for further experiments were screened in medium in the presence of G418 $(0.5 \mu \mathrm{g} / \mu \mathrm{l})$.

Real-time quantitative PCR (RT-qPCR). Whole RNA in the different samples was extracted using RNAsimple Total RNA kit according to the manufacturer's instructions (no. DP419; Tiangen, Beijing, China). GAPDH was selected as the reference gene. Then, the RNA was reversely transcribing to cDNA templates using Super M-MLV Reverse Transcriptase (no. RP6502; BioTeke, Beijing, China). The final RT-qPCR reaction mixture of volume $20 \mu \mathrm{l}$ consisted of $10 \mu \mathrm{l}$ of SYBR-Green Master Mix, $0.5 \mu \mathrm{l}$ of each primer (LASP-1 forward, 5'-TTCCATTGCGAGACCTGC-3' and reverse, 5'-TGCCACTACGCTGAAACCT-3'; P65 forward, 5'-CTTACACTTAGCAATCATCCACCTT-3' and reverse, 5'-GCAAATCCTCCACCACATCTT-3'; I $\kappa \mathrm{B} \alpha$ forward, 5'-CTGATGGAGTACCCTGAGGCTAT-3' and reverse, 5'-TGTCCGCAATGGAGGAGAAGT-3'; GAPDH forward, 5'-TATGATGATATCAAGAGGGTAGT-3' and reverse, 5'-TGTATCCAAACTCATTGTCATAC-3'), $1 \mu$ l of the cDNA template, and $8 \mu \mathrm{l}$ of RNase-free $\mathrm{H}_{2} \mathrm{O}$. Thermal cycling parameters for the amplification were set-up as follows: a denaturation step at $94^{\circ} \mathrm{C}$ for $2 \mathrm{~min}$, followed by 40 cycles at $94^{\circ} \mathrm{C}$ for $20 \mathrm{sec}$, $58^{\circ} \mathrm{C}$ for $20 \mathrm{sec}$ and $72^{\circ} \mathrm{C}$ for $20 \mathrm{sec}$. Relative expression level of the targeted gene was calculated with Exicycler ${ }^{\mathrm{TM}} 96$ (Bioneer, Daejeon, Korea) according to the method $2^{-\Delta \Delta \mathrm{Ct}}$.

Western blot analysis. Protein product of different samples was extracted using Whole Protein Extraction kit according to the manufacturer's instructions (WLA019; Wanleibio, Shenyang, China) and GAPDH was used as a reference protein. The concentration of the extracted protein samples was determined according to the BCA method. For western blot assay, $40 \mu \mathrm{g}$ of protein in $20 \mu \mathrm{l}$ solution was subject to a $13 \%$ sodium dodecylsulfate polyacrylamide gel electrophoresis (SDS-PAGE), and the proteins were subsequently transferred onto polyvinylidene difluoride (PVDF) membranes. Then, the membranes were washed in TTBS for $5 \mathrm{~min}$ and incubated with $5 \%$ skim milk powder solution for $1 \mathrm{~h}$. The primary antibody against LASP-1 (1:1,500), P65 (1:2,000), IкB $\alpha(1: 2,000)$ or GAPDH $(1: 1,000)$ was added into the solution and incubated with the membranes at $4^{\circ} \mathrm{C}$ overnight. The membranes were then washed with TTBS four times and incubated with secondary IgG-HRP antibodies $(1: 20,000)$ for $45 \mathrm{~min}$ at $37^{\circ} \mathrm{C}$. After the final six washes with TTBS, the blots were developed using Beyo ECL Plus reagent and the results were observed using a gel imaging system. The relative expression levels of LASP-1 in the different groups were calculated with Gel-Pro Analyzer (Media Cybernetics, Inc., Rockville, MD, USA).

$C C K-8$ assay. The cell viability of the PCa cells in the different groups was measured by Cell Counting Kit-8 (CCK-8) assay. In brief, $50 \mu \mathrm{l}$ of exponentially growing cells $\left(3 \times 10^{3}\right.$ cells $\left./ \mathrm{ml}\right)$ were seeded into one well of a 96-well plate and cultured for $24 \mathrm{~h}$. Each group was represented by 20 replicates and the cell viability of five randomly selected wells at 24, 48, 72 and $96 \mathrm{~h}$ 
Table I. Clinicopathological information of the patients employed for clinical tissue collection.

\begin{tabular}{|c|c|c|c|c|c|}
\hline No. & $\begin{array}{c}\text { PCa or } \\
\text { non-PCa }\end{array}$ & $\begin{array}{l}\text { Age } \\
\text { (years) }\end{array}$ & $\begin{array}{l}\text { PSA } \\
(\mathrm{ng} / \mathrm{ml})\end{array}$ & $\begin{array}{c}\text { Free/total } \\
\text { PSA ratio }(\mathrm{f} / \mathrm{t})\end{array}$ & $\begin{array}{c}\text { Gleason } \\
\text { score }\end{array}$ \\
\hline 1 & $\mathrm{PCa}$ & 68 & 133.2 & 0.14 & $5+4$ \\
\hline 2 & $\mathrm{PCa}$ & 55 & 1.25 & 0.26 & $4+5$ \\
\hline 3 & $\mathrm{PCa}$ & 72 & 43.0 & 0.11 & $4+4$ \\
\hline 4 & $\mathrm{PCa}$ & 83 & 14.0 & 0.10 & $4+3$ \\
\hline 5 & $\mathrm{PCa}$ & 70 & 89.6 & 0.05 & $4+4$ \\
\hline 6 & $\mathrm{PCa}$ & 65 & 28.6 & 0.14 & $3+4$ \\
\hline 7 & $\mathrm{PCa}$ & 75 & 209.6 & 0.04 & $4+4$ \\
\hline 8 & $\mathrm{PCa}$ & 83 & 31.3 & 0.07 & $4+4$ \\
\hline 9 & $\mathrm{PCa}$ & 62 & 6.29 & 0.12 & $3+3$ \\
\hline 10 & $\mathrm{PCa}$ & 67 & 7.5 & 0.22 & $3+3$ \\
\hline 11 & $\mathrm{PCa}$ & 74 & 10.7 & 0.15 & $3+3$ \\
\hline 12 & $\mathrm{PCa}$ & 75 & 100 & 0.56 & $4+5$ \\
\hline 13 & $\mathrm{PCa}$ & 83 & 575.6 & 0.06 & $4+4$ \\
\hline 14 & $\mathrm{PCa}$ & 78 & 152.1 & 0.06 & $4+4$ \\
\hline 15 & $\mathrm{PCa}$ & 76 & 9.47 & 0.06 & $2+3$ \\
\hline 1 & Non-PCa & & & & \\
\hline 2 & Non-PCa & & & & \\
\hline 3 & Non-PCa & & & & \\
\hline 4 & Non-PCa & & & & \\
\hline 5 & Non-PCa & & & & \\
\hline 6 & Non-PCa & & & & \\
\hline 7 & Non-PCa & & & & \\
\hline 8 & Non-PCa & & & & \\
\hline 9 & Non-PCa & & & & \\
\hline 10 & Non-PCa & & & & \\
\hline 11 & Non-PCa & & & & \\
\hline 12 & Non-PCa & & & & \\
\hline 13 & Non-PCa & & & & \\
\hline 14 & Non-PCa & & & & \\
\hline 15 & Non-PCa & & & & \\
\hline
\end{tabular}

PCa, prostate cancer; PSA, prostate-specific antigen.

was determined, respectively. For each well, CCK-8 solution $(10 \mu \mathrm{l})$ was added and the cultures were incubated at $37^{\circ} \mathrm{C}$ for $1 \mathrm{~h}$. The optical density (OD) values at $450 \mathrm{~nm}$ in different wells were recorded using a mircoplate reader.

Flow cytometry. Cell cycle distribution and apoptotic rates in the different groups were determined using flow cytometry. Cells in the different groups were collected using centrifugation at 2,000 rpm for $5 \mathrm{~min}$. Cell cycle distribution was detected according to standard procedure. In brief, the cells were fixed with $70 \%$ alcohol at $4^{\circ} \mathrm{C}$ for $2 \mathrm{~h}$. Then, $500 \mu \mathrm{l}$ propidium iodide (PI)-FITC was added to the different samples to stain DNA in the dark at $4^{\circ} \mathrm{C}$ for $30 \mathrm{~min}$. After a 20 -min incubation at room temperature, the DNA contents of the cells were analyzed using a flow cytometer (BD Accuri C6; BD Biosciences, San Jose, CA, USA). Then, the cell apoptotic rates were also measured using an Annexin V-FITC apoptosis detection kit (WLA001c;
Wanleibio) according to the manufacturer's instructions. In brief, $5 \mu \mathrm{l}$ of Annexin $\mathrm{V}$ was added to the different wells. After incubation with Annexin V for $10 \mathrm{~min}$ at room temperature, the cells were resuspended with $1 \mathrm{X}$ binding buffer and $5 \mu \mathrm{l}$ PI was added. Then, the apoptotic rates were analyzed using a FACScan flow cytometry (Accuri C6). The apoptotic cells (UR + LR quadrants; the percentage of early and late apoptotic cells) was equal to the sum of the late apoptotic cells (UR, upper right quadrant; percentage of advanced stage apoptotic cells) and the early apoptotic cells (LR, lower right quadrant; percentage of prophase apoptotic cells).

Transwell experiment. The Transwell experiment which evaluated the migration ability of PCa cells in the different groups was performed. An amount of $200 \mu \mathrm{l}$ incubation (with $1 \mathrm{mM} \mathrm{MgCl} 2$ ) medium containing $1 \times 10^{4}$ cells were seeded into the upper chamber of Transwell chambers (Corning Star, Cambridge, MA, USA). Then, the cells were incubated at $37^{\circ} \mathrm{C}$ for $24 \mathrm{~h}$ to allow migration through the porous membrane. Upon completion of the culture, the cells remaining on the upper surface of the chamber were completely removed. The lower surfaces of the membranes were fixed with $4 \%$ paraformaldehyde for $20 \mathrm{~min}$ and stained in a solution containing $0.5 \%(\mathrm{w} / \mathrm{v})$ crystal violet for $5 \mathrm{~min}$. After being washed using $\mathrm{ddH}_{2} \mathrm{O}$, the numbers of cells in the different groups were determined using Image-Pro Plus 6.0 software (Nikon, Tokyo, Japan). Then, the invasion ability of the PCa cells was measured as described above with polycarbonate membranes being previously coated with $40 \mu$ l Matrigel $\left(1.5 \mathrm{mg} / \mathrm{ml}\right.$; BD Biosciences) at $37^{\circ} \mathrm{C}$ for $2 \mathrm{~h}$ to form a reconstituted basement membrane.

Statistical analysis. All the data are expressed in the form of mean \pm SD. Student's t-test was performed and a significant level of 0.05 was assigned. Statistical analysis was carried out using GraphPad Prism 6 (GraphPad Software, Inc., San Diego, CA, USA).

\section{Results}

LASP-1 expression in clinical samples is upregulated. To investigate the status of expression of LASP-1 in clinical samples, the mRNA and protein levels in 15 pairs of $\mathrm{PCa}$ specimens and corresponding para-carcinoma tissues were detected. All the PCa samples showed upregulation of LASP-1 expression when compared with the levels in their corresponding para-carcinoma tissues, and the average difference between carcinoma and para-carcinoma samples was statistically significant $(\mathrm{P}<0.05)$ (Fig. 1).

LASP-1 knockdown attenuates the viability of the PC3 and DU145 cells. The cell viability of the cells following the different treatments was quantified using the CCK-8 assay. As shown in Fig. 2A, compared with control and NC groups, transfection of LASP-1-specific shRNA decreased the proliferation of the PC 3 cells in the shRNA group at $48 \mathrm{~h}$ of the assay, and the differences between NC and shRNA groups were statistically significant for the last three time points $(\mathrm{P}<0.05)$ (Fig. 2A). Similar results were also detected for the DU145 cells. Inhibition of LASP-1 in the PCa cells significantly decreased the cell viability (Fig. 2B). 


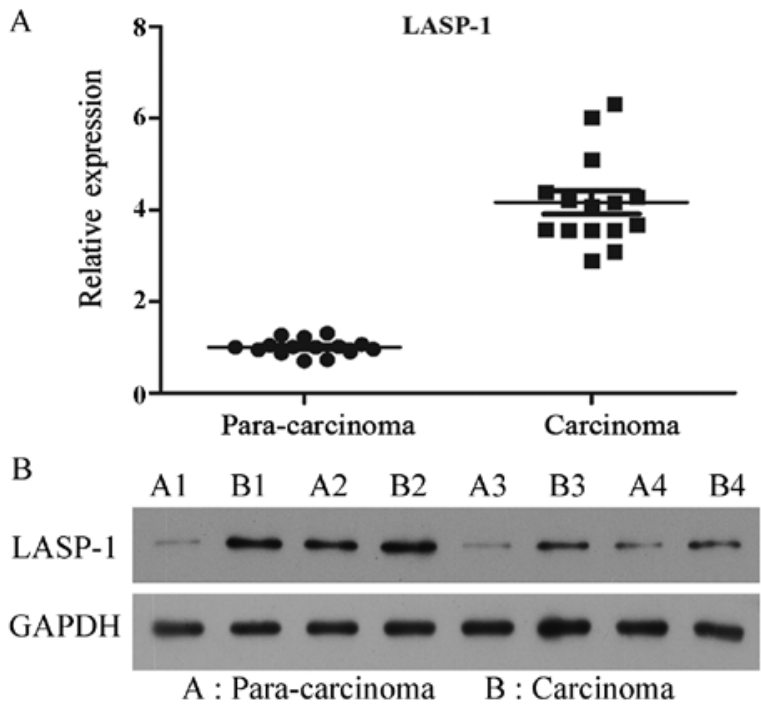

Figure 1. Expression of LASP-1 is upregulated in clinical prostate cancer (PCa) samples. (A) Quantitative analysis of the RT-qPCR results in the clinical samples. The expression levels of LASP-1 in all PCa patient samples were higher than those in their corresponding controls. (B) Representative images of western blot assay of four pairs of randomly selected clinical samples.
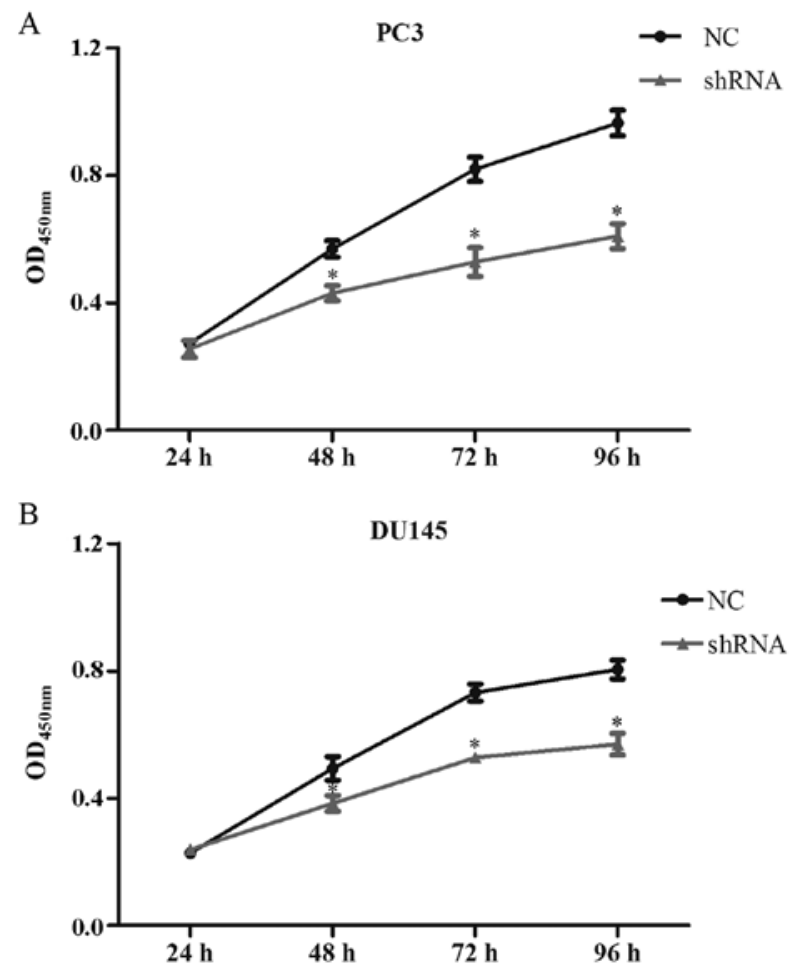

Figure 2. Knockdown of LASP-1 attenuates the cell viability of both prostate cancer cell lines. (A) Quantitative analysis results of cell viability of PC3 cells. (B) Quantitative analysis results of cell viability of DU145 cells. ${ }^{*} \mathrm{P}<0.05$, significantly different from the $\mathrm{NC}$ group.

LASP-1 knockdown increases cell apoptosis and induces cell cycle arrest in the PC3 and DU145 cells. Apoptosis and cell cycle distribution of cells in the different groups were analyzed by flow cytometry. After knockdown of LASP-1, late apoptotic $(13.8 \pm 1.3 \%)$ and early apoptotic rates $(20.4 \pm 3.1 \%)$ of the PC3 cells transfected with LASP-1-specific shRNA were
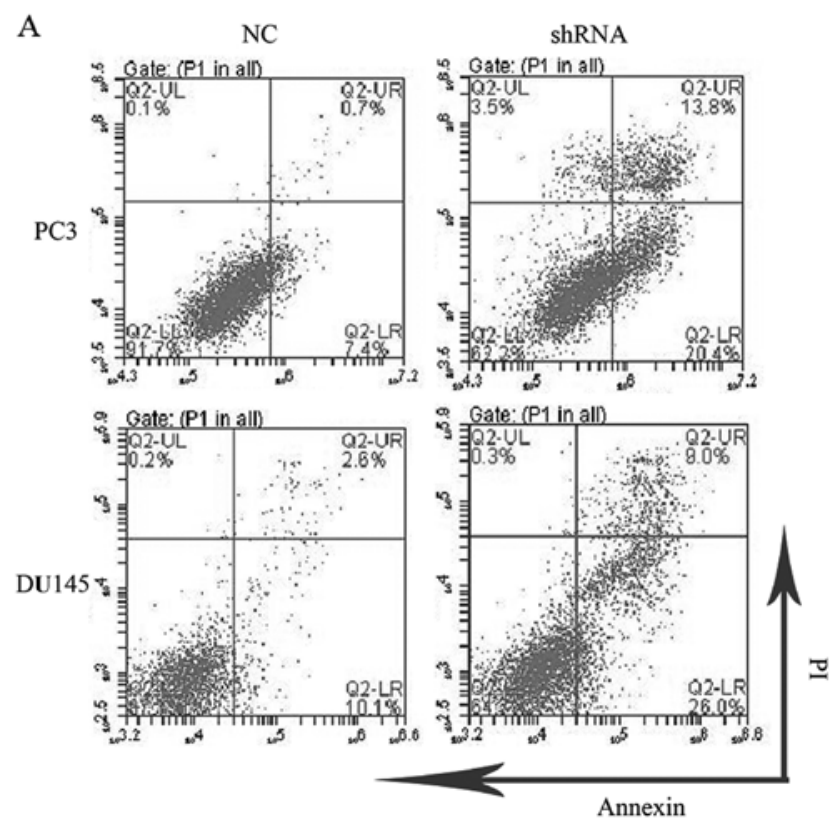

B

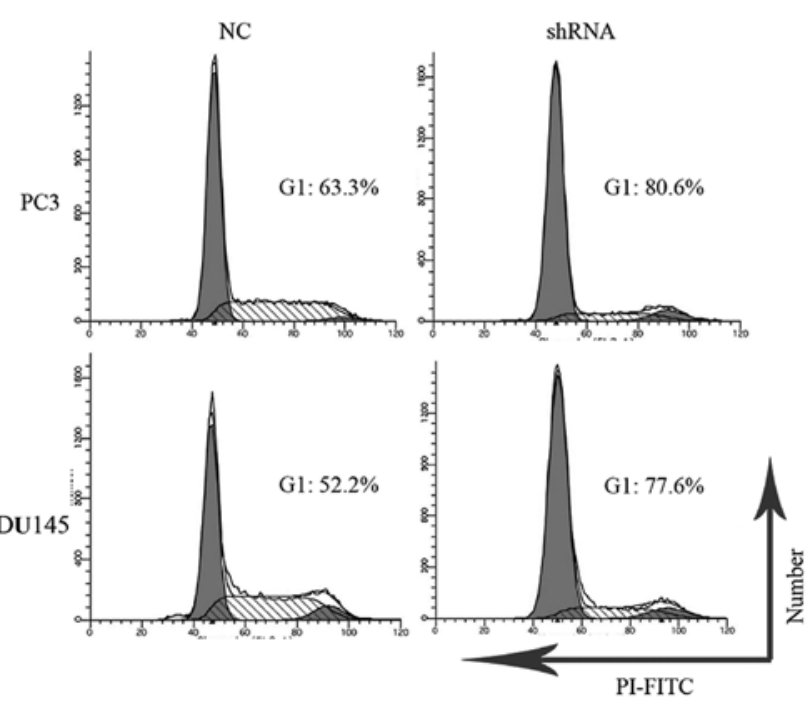

Figure 3. Knockdown of LASP-1 induces the apoptosis and G1 phase cell cycle arrest in both prostate cancer cell lines. (A) Representative images of the apoptotic rates. (B) Representative images of cell cycle distribution.

increased compared with those in the $\mathrm{NC}$ groups $(0.7 \pm 0.02 \%$ for late apoptotic rate and $7.4 \pm 1.7 \%$ for early apoptotic rate) (Fig. 3A). Similar changes were observed for DU145 cells as well (Fig. 3A). As illustrated in Fig. 3B, PC3 cells following LASP-1 knockdown treatment showed G1 arrest by increasing the percentage of cells in the G1 phase $(80.6 \pm 2.3 \%)$, which was markedly different from the results of the NC group $(63.4 \pm 1.9 \%)$. The downregulation of LASP-1 in the PC 3 cells also resulted in a concomitant decrease in the fraction of cells in the S phase, revealing that inhibition of LASP-1 could halt the cell proliferation of PC3 cells via cell cycle arrest at the G1 phase. A similar change in the pattern of cell cycle distribution was also recorded for the DU145 cells (Fig. 3B).

LASP-1 knockdown decreases cell migration and invasion ability of the PC3 and DU145 cells. The effect of LASP-1 on 
A

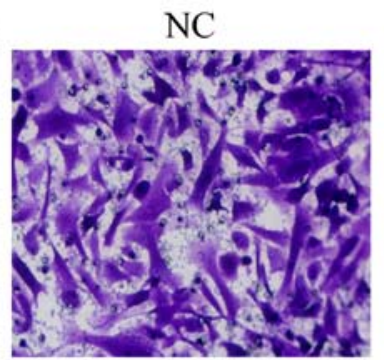

B

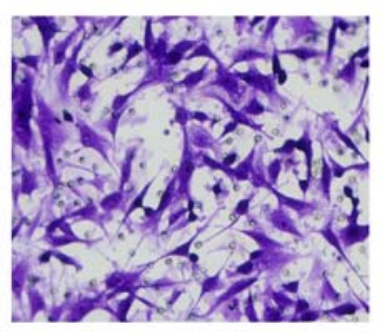

C

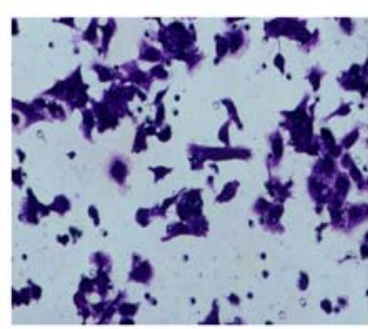

D

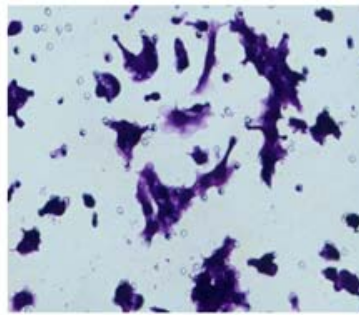

shRNA
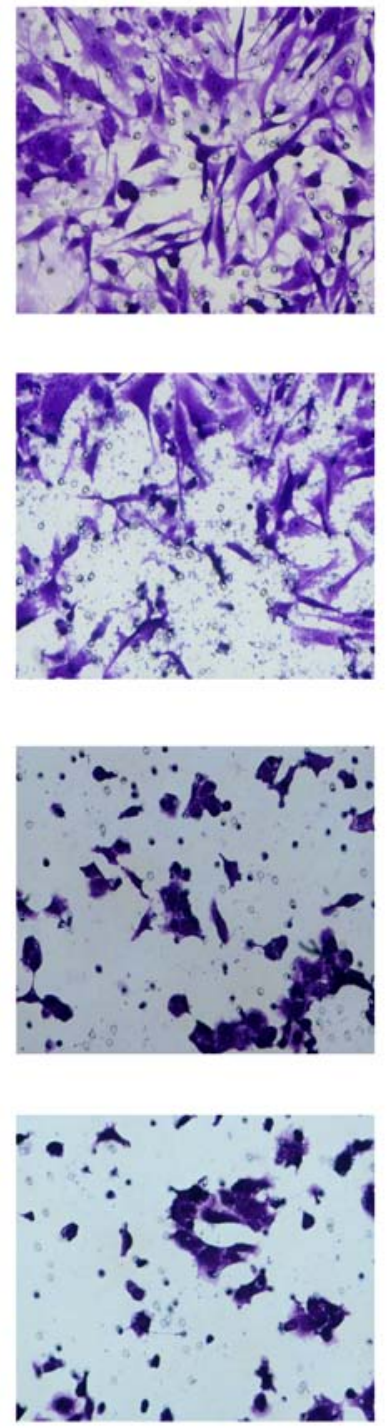
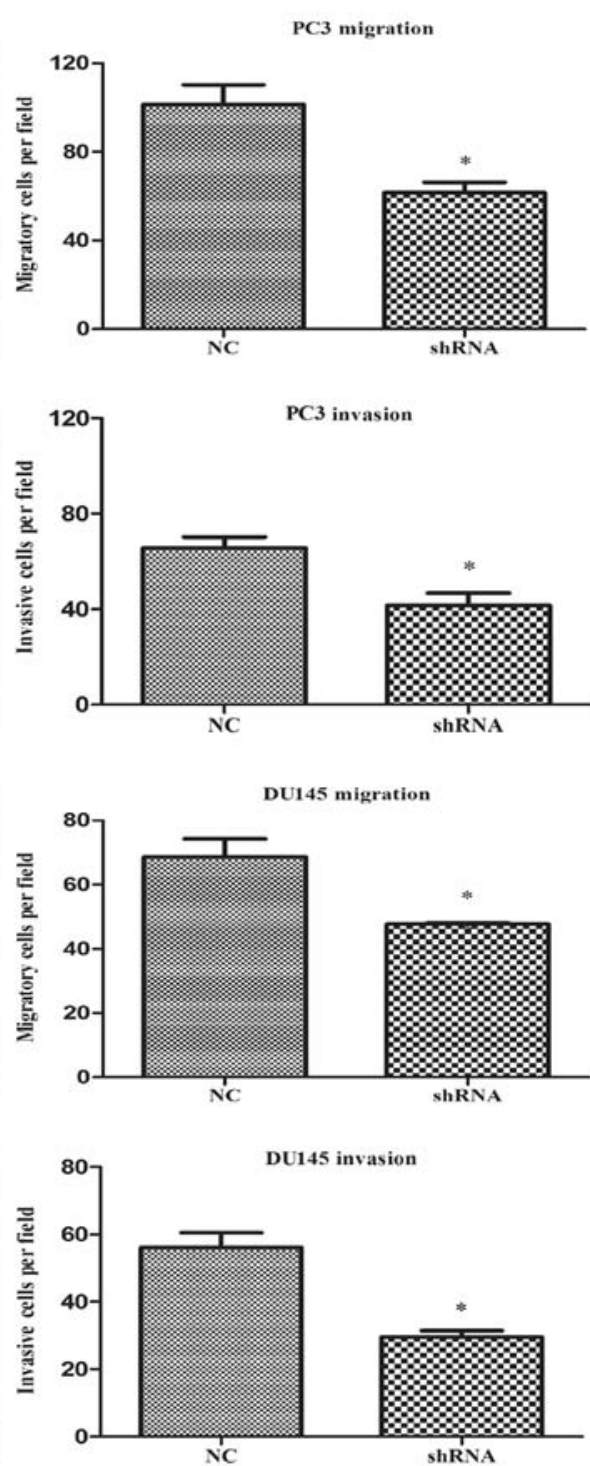

Figure 4. Knockdown of LASP-1 decreases the cell migration and invasion ability in both prostate cancer (PCa) cell lines. (A) Representative images and quantitative analysis of the effect of LASP-1 knockdown on the migration ability of PC3 cells. (B) Representative images and quantitative analysis of the effect of LASP-1 knockdown on the invasion ability of PC3 cells. (C) Representative images and quantitative analysis of the effect of LASP-1 knockdown on the migration ability of DU145 cells. (D) Representative images and quantitative analysis of the effect of LASP-1 knockdown on the invasion ability of DU145 cells. ${ }^{*} \mathrm{P}<0.05$, significantly different from the NC group; .

the migration of PCa cells was determined using Transwell assay. For measurement of the cell invasion ability, the polycarbonate membranes were previously coated with Matrigel to form a reconstituted basement membrane. As shown in Fig. 4A and B, the numbers of cells migrating through the porous membrane in the shRNA group ( $62 \pm 4$ for migration and $42 \pm 2$ for invasion assays) were significantly lower than those in the NC group (102 \pm 4 for migration assay and $62 \pm 2$ for invasion assay) $(\mathrm{P}<0.05)$, indicating an inhibitory effect on the cell motile ability due to the knockdown of LASP-1. Similar to the migration and invasion abilities of the PC3 cells, knockdown of LASP-1 in DU145 cells also resulted in a decrease in migration and invasion abilities (Fig. 4C and D).

LASP-1 knockdown downregulates the expression of $N F-\kappa B$-related molecules. To explore the mechanism which drives the effect of LASP-1 knockdown on the biological alterations in PCa cells, the expression of LASP-1, P65 and
I $\mathrm{B} \alpha$ was quantified with RT-qPCR and western blot assay. It was found that inhibition of LASP-1 suppressed the expression of all three indicators at both the mRNA and protein levels (Figs. 5 and 6). Based on the quantitative analysis, the difference between shRNA and NC groups was statistically significant $(\mathrm{P}<0.05)$. The result of RT-qPCR and western blot assay demonstrated that LASP-1 may play a role in the carcinogenesis of PCa through a NF- $\mathrm{BB}-d e p e n d e n t$ manner.

\section{Discussion}

Despite the progress in the treatment of prostate cancer in the past few decades, PCa remains a major cause of health issues worldwide among males. Traditional treatments including surgery and radiation therapies seem to be less effective against PCa cases once metastasis occurs. Thus, identification of the biological markers related to oncogenesis and mobility of $\mathrm{PCa}$ cells is crucial for the development of therapeutic strategies to 

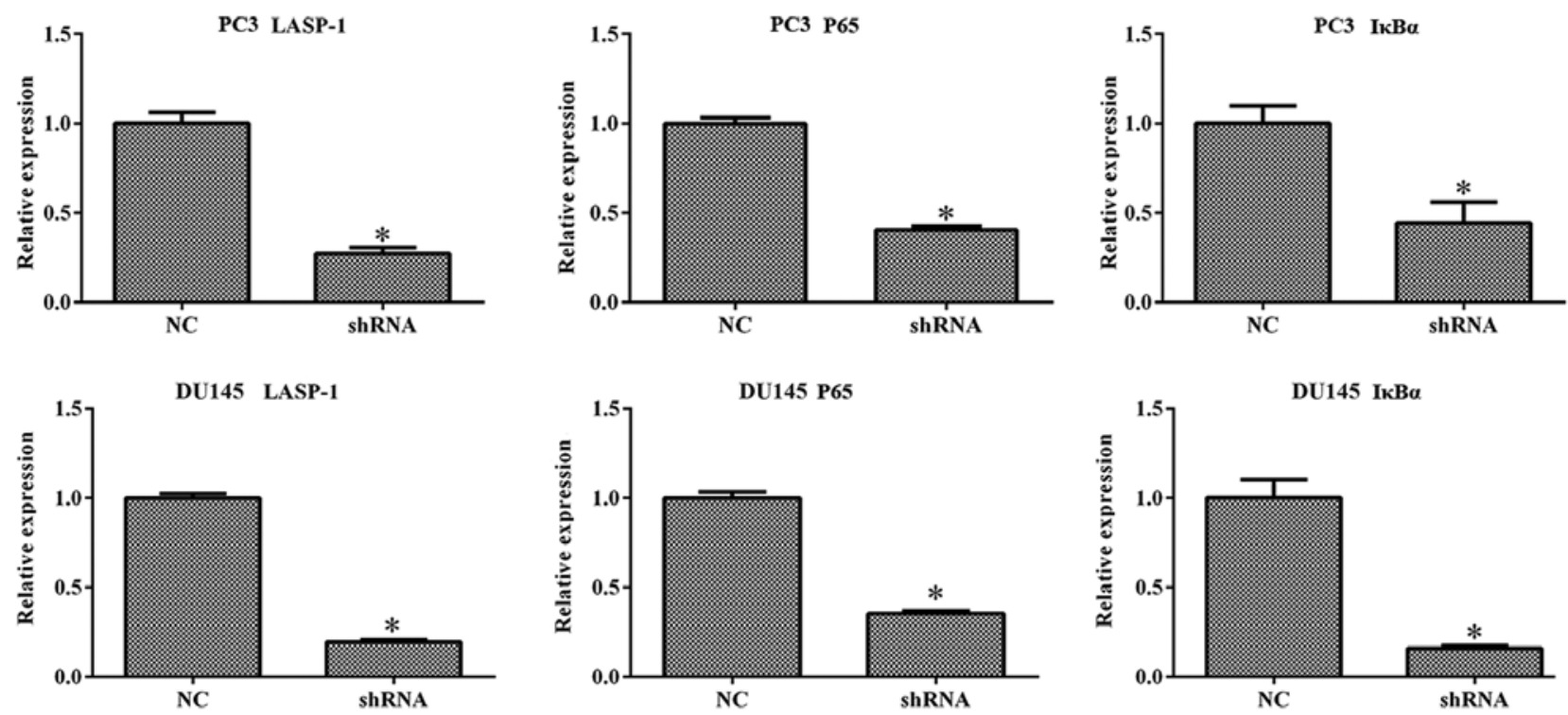

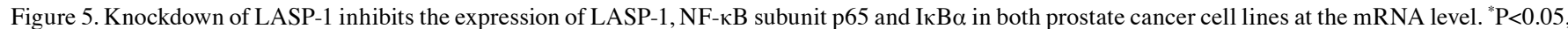
significantly different from the $\mathrm{NC}$ group.

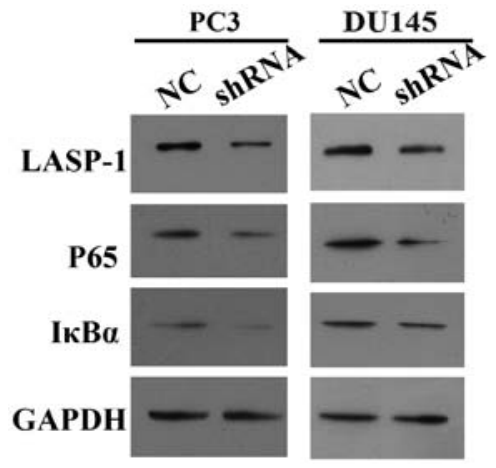

Figure 6. Knockdown of LASP-1 inhibits the expression of LASP-1, NF-кB subunit p65 and IкB $\alpha$ in both prostate cancer cell lines at the protein level.

improve the outcome and survival of this malignant cancer. In the present study, the expression of an important tumorassociated factor, LASP-1 in clinical PCa tissues and its function in the carcinogenesis of PCa were investigated for the first time. It was demonstrated that both LASP-1 mRNA and protein levels were significantly upregulated in clinical PCa tissues. Experimental observation based on the knockdown of the LASP-1 gene in human PCa cell lines PC3 and DU145 also clearly inferred that while growth and movement of PCa cells were attenuated, the apoptotic process was induced. All of these results suggest a key role of LASP-1 in the proliferation and motility of PCa cells.

The central role of LASP-1 in the progression and metastasis of various types of cancers was previously investigated (14-18). Results of the present study further support the conclusions of these studies by verifying the important function of LASP-1 in PCa. In clinical PCa samples, the production of LASP-1 at the mRNA and proteins levels was enhanced. Moreover, knockdown of LASP-1 in human PCa cell lines resulted in a deteriorating effect on cell growth. Furthermore, flow cytometric assay also showed that the decrease in cell proliferation in response to LASP-1-specific shRNA treatment was accompanied by the induction of cell apoptosis and G1 phase cell cycle arrest. However, contradiction regarding the function of LASP-1 in cancer cell viability still exists. According to the study of Grunewald et al (14), no significant influence of LASP-1 knockdown on the apoptotic process in BT-20 and MCF-7 cell lines was observed. Although the two studies focused on distinct cancer types, this information is indicative of the complicated mechanism of LASP-1 in regulating cancer cell apoptosis.

LASP-1 is a well-known focal adhesion adaptor protein and is closely associated with the modulation of cytoskeleton and cancer cell migration and invasion (12,25-27). The factor is capable of interacting and co-localizing with a series of focal adhesion proteins, such as F-actin, zyxin and LPP. Thus, silencing of LASP-1 causes cellular localization change of its binding partners at the focal adhesion site and influences the mobility of cells. In the present study, it was found that cells treated with LASP-1-specific shRNA exhibited a significant decrease in cell migration and invasion ability, which proved the critical function of LASP-1 in the metastasis of cancer cells as well. However, as previously reported, cells depleted of LASP-1 may still attach to the extracellular matrix (ECM) and form focal adhesions. It is hypothesized that the molecule may play a supportive role in focal adhesion dynamics rather than actual formation of the related structures (25).

To further elucidate the mechanism through which LASP-1 exerts its function in the onset and development of $\mathrm{PCa}$, the interaction between LASP-1 and NF- $\mathrm{KB}$ was investigated. $\mathrm{NF}-\kappa \mathrm{B}$ is a transcriptional factor which regulates the apoptosis and inflammation in various diseases (28). The inactive form of NF- $\kappa \mathrm{B}$ is sequestered in the cytoplasm by binding with

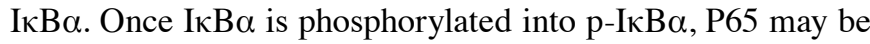
translocated into the nucleus and activates transcription of the targeted genes. In the present study, the results showed that LASP-1-specific shRNA reduced NF- $\kappa$ B production and P65 translocation to the nucleus, which would lead to the inhibition 
of NF- $\kappa \mathrm{B}$ activity. In fact, activation of NF- $\kappa \mathrm{B}$ has been implicated in both carcinogenesis and drug resistance in cancer cells (29). Thus, inhibition of $\mathrm{NF}-\kappa \mathrm{B}$ activation may represent a promising opportunity for expanding therapeutic windows in translational cancer research $(30,31)$. Considering the high efficiency of LASP-1 knockdown in attenuating NF- $\mathrm{BB}$ activity in the present study, it was reasonable to demonstrate that therapies based on LASP-1 interference may antagonize $\mathrm{PCa}$ through a NF- $\mathrm{B}$ inhibition-dependent manner.

Conclusively, the major findings outlined in the present study elucidated that the expression of LASP-1 was abnormally high in clinical PCa tissues, and following knockdown of LASP-1 in human PCa cell lines, the proliferation and mobility of cancer cells were markedly inhibited. Preliminarily, it was hypothesized that LASP-1 may activate the carcinogenesis of PCa through an NF- $\mathrm{BB}$-dependent manner. Although a detailed explanation of the effect of LASP-1 on PCa was not fully elucidated, the present study highlights that LASP-1 has the potential to be a promising target for alleviation of $\mathrm{PCa}$ in the clinic. To elaborate the role of LASP-1 in PCa, more comprehensive studies need to be conducted in the future.

\section{Acknowledgements}

The present study was supported by the Science and Technology Development Plan Project of Medical and Health in Shandong Province (no. 2007QW016), the Seed Fund of the Second Hospital of Shandong University and the Key Clinical Program of the Ministry of Health.

\section{References}

1. Howlader N, Noone AM, Krapcho M, Neyman N, Aminou R, Waldron W, Altekruse SF, Kosary CL, Ruhl J, Tatalovich Z, et al (eds): SEER Cancer Statistics Review, 1975-2008. National Cancer Institute, Bethesda, MD, 2011. http://seer.cancer.gov/ csr/1975_2008/.

2. Siegel RL , Miller KD and Jemal A: Cancer statistics, 2015. CA Cancer J Clin 65: 5-29, 2015.

3. Zhu Y, Yang XQ, Han CT, Dai B, Zhang HL, Shi GH, Wang CF and Ye DW: Pathological features of localized prostate cancer in China: A contemporary analysis of radical prostatectomy specimens. PLoS One 10: e0121076, 2015.

4. Garg M, Dalela D, Goel A, Kumar M and Sankhwar SN: Prevention of prostate cancer with vitamins - current perspectives. Asian Pac J Cancer Prev 15: 1897-1904, 2014.

5. Euling SY and Kimmel CA: Developmental stage sensitivity and mode of action information for androgen agonists and antagonists. Sci Total Environ 274: 103-113, 2001.

6. Bickers B and Aukim-Hastie C: New molecular biomarkers for the prognosis and management of prostate cancer - the post PSA era. Anticancer Res 29: 3289-3298, 2009.

7. Siddiqui E, Mumtaz FH and Gelister J: Understanding prostate cancer. J R Soc Promot Health 124: 219-221, 2004.

8. Hudson RS, Yi M, Esposito D, Watkins SK, Hurwitz AA, Yfantis HG, Lee DH, Borin JF, Naslund MJ, Alexander RB, et al: MicroRNA-1 is a candidate tumor suppressor and prognostic marker in human prostate cancer. Nucleic Acids Res 40: 3689-3703, 2012.

9. Hailer A, Grunewald TG, Orth M, Reiss C, Kneitz B, Spahn M and Butt E: Loss of tumor suppressor mir-203 mediates overexpression of LIM and SH3 protein 1 (LASP1) in high-risk prostate cancer thereby increasing cell proliferation and migration. Oncotarget 5: 4144-4153, 2014.

10. Nishikawa R, Goto Y, Sakamoto S, Chiyomaru T, Enokida H, Kojima S, Kinoshita T, Yamamoto N, Nakagawa M, Naya Y, et al: Tumor-suppressive microRNA-218 inhibits cancer cell migration and invasion via targeting of $L A S P 1$ in prostate cancer. Cancer Sci 105: 802-811, 2014.
11. Viticchiè G, Lena AM, Latina A, Formosa A, Gregersen LH, Lund AH, Bernardini S, Mauriello A, Miano R, Spagnoli LG, et al: MiR-203 controls proliferation, migration and invasive potential of prostate cancer cell lines. Cell Cycle 10: 1121-1131, 2011.

12. Chew CS, Chen X, Parente JA Jr, Tarrer S, Okamoto C and Qin HY: Lasp-1 binds to non-muscle F-actin in vitro and is localized within multiple sites of dynamic actin assembly in vivo. J Cell Sci 115: 4787-4799, 2002.

13. Nakagawa H, Terasaki AG, Suzuki H, Ohashi K and Miyamoto S: Short-term retention of actin filament binding proteins on lamellipodial actin bundles. FEBS Lett 580: 3223-3228, 2006.

14. Grunewald TG, Kammerer U, Schulze E, Schindler D, Honig A, Zimmer $M$ and Butt E: Silencing of LASP-1 influences zyxin localization, inhibits proliferation and reduces migration in breast cancer cells. Exp Cell Res 312: 974-982, 2006.

15. Zhao L, Wang H, Liu C, Liu Y, Wang X, Wang S, Sun X, Li J, Deng Y, Jiang Y, et al: Promotion of colorectal cancer growth and metastasis by the LIM and SH3 domain protein 1. Gut 59: 1226-1235, 2010

16. Salvi A, Bongarzone I, Miccichè F, Arici B, Barlati S and De Petro G: Proteomic identification of LASP-1 down-regulation after RNAi urokinase silencing in human hepatocellular carcinoma cells. Neoplasia 11: 207-219, 2009

17. Wang $\mathrm{H}$, Li W, Jin X, Cui S and Zhao L: LIM and SH3 protein 1 , a promoter of cell proliferation and migration, is a novel independent prognostic indicator in hepatocellular carcinoma. Eur J Cancer 49: 974-983, 2013

18. Chiyomaru T, Enokida H, Kawakami K, Tatarano S, Uchida Y, Kawahara K, Nishiyama K, Seki N and Nakagawa M: Functional role of LASP1 in cell viability and its regulation by microRNAs in bladder cancer. Urol Oncol 30: 434-443, 2012.

19. Miyamoto $\mathrm{S}$ and Verma IM: Rel/NF-kappa B/I kappa B story. Adv Cancer Res 66: 255-292, 1995.

20. Bargou RC, Emmerich F, Krappmann D, Bommert K, Mapara MY, Arnold W, Royer HD, Grinstein E, Greiner A, Scheidereit C, et al: Constitutive nuclear factor-kappaB-RelA activation is required for proliferation and survival of Hodgkin's disease tumor cells. J Clin Invest 100: 2961-2969, 1997.

21. Pikarsky E, Porat RM, Stein I, Abramovitch R, Amit S, Kasem S, Gutkovich-Pyest E, Urieli-Shoval S, Galun E and Ben-Neriah Y: NF-kappaB functions as a tumour promoter in inflammation-associated cancer. Nature 431: 461-466, 2004.

22. Kim SM, Lee SY, Yuk DY, Moon DC, Choi SS, Kim Y, Han SB, Oh KW and Hong JT: Inhibition of NF-kappaB by ginsenoside $\operatorname{Rg} 3$ enhances the susceptibility of colon cancer cells to docetaxel. Arch Pharm Res 32: 755-765, 2009.

23. Suh J, Payvandi F, Edelstein LC, Amenta PS, Zong WX, Gélinas C and Rabson AB: Mechanisms of constitutive NF-kappaB activation in human prostate cancer cells. Prostate 52: $183-200,2002$.

24. Herrmann JL, Beham AW, Sarkiss M, Chiao PJ, Rands MT, Bruckheimer EM, Brisbay S and McDonnell TJ: Bcl-2 suppresses apoptosis resulting from disruption of the NF- $\kappa \mathrm{B}$ survival pathway. Exp Cell Res 237: 101-109, 1997.

25. Butt E, Gambaryan S, Göttfert N, Galler A, Marcus K and Meyer HE: Actin binding of human LIM and SH3 protein is regulated by cGMP- and cAMP-dependent protein kinase phosphorylation on serine 146. J Biol Chem 278: 15601-15607, 2003.

26. Li B, Zhuang L and Trueb B: Zyxin interacts with the SH3 domains of the cytoskeletal proteins LIM-nebulette and Lasp-1. J Biol Chem 279: 20401-20410, 2004.

27. Schreiber V, Moog-Lutz C, Régnier CH, Chenard MP, Boeuf H, Vonesch JL, Tomasetto C and Rio MC: Lasp-1, a novel type of actin-binding protein accumulating in cell membrane extensions. Mol Med 4: 675-687, 1998.

28. Mattson MP: NF-kappaB in the survival and plasticity of neurons. Neurochem Res 30: 883-893, 2005.

29. Li Y, Ellis KL, Ali S, El-Rayes BF, Nedeljkovic-Kurepa A, Kucuk O, Philip PA and Sarkar FH: Apoptosis-inducing effect of chemotherapeutic agents is potentiated by soy isoflavone genistein, a natural inhibitor of NF-kappaB in BxPC-3 pancreatic cancer cell line. Pancreas 28: e90-e95, 2004.

30. Qin Z-H, Wang Y, Nakai M and Chase TN: Nuclear factor- $\kappa$ B contributes to excitotoxin-induced apoptosis in rat striatum. Mol Pharmacol 53: 33-42, 1998.

31. Beg AA and Baltimore D: An essential role for NF-kappaB in preventing TNF-alpha-induced cell death. Science 274: 782-784, 1996. 